\title{
Acquired isolated diverticulum at the ileocecal valve presenting as massive hematochezia: an unusual location and cause of gastrointestinal bleeding
}

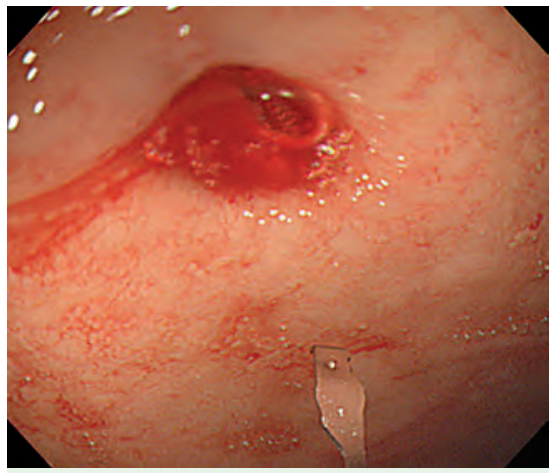

Fig. 1 Endoscopic view of the actively bleeding diverticulum located just proximal to the upper lip of the ileocecal valve. A metal clip could not be applied because of the anatomic location of the lesion.

An acquired diverticulum in the small intestine is a rare condition and may be a cause of lower gastrointestinal bleeding [1 - 3]. We report a case of acquired diverticulum at the ileocecal valve presenting as massive hematochezia.

A 52-year-old woman was hospitalized with sudden-onset hematochezia. On admission, an urgent colonoscopy found no acute bleeding lesions in the large intestine. After passing the ileocecal valve, a small, actively bleeding diverticulum was noted just proximal to the upper lip of the ileocecal valve ( $\bullet$ Fig. 1). Its unusual anatomic location made endoscopic intervention impossible. Neither changing the patient's position, nor attaching a transparent hood in the distal end, was helpful, and the bleeding was controlled by therapeutic angiography ( $\bullet$ Fig. 2 ). However, the patient had recurrent massive bleeding the next day, and $12 \mathrm{~cm}$ of the ileocecal region was surgically resected. The resected specimen contained a 5$\mathrm{mm}$ diverticulum at the junction of the ileocecal valve and the terminal ileum, along the mesenteric border ( $\bullet$ Fig. 3 ). Histological examination of the specimen confirmed the presence of a false diverticulum consisting of mucosa and connective tissue associated with infiltrating inflammatory cells ( $\bullet$ Fig. 4). A small-bowel series showed no diverticula else-

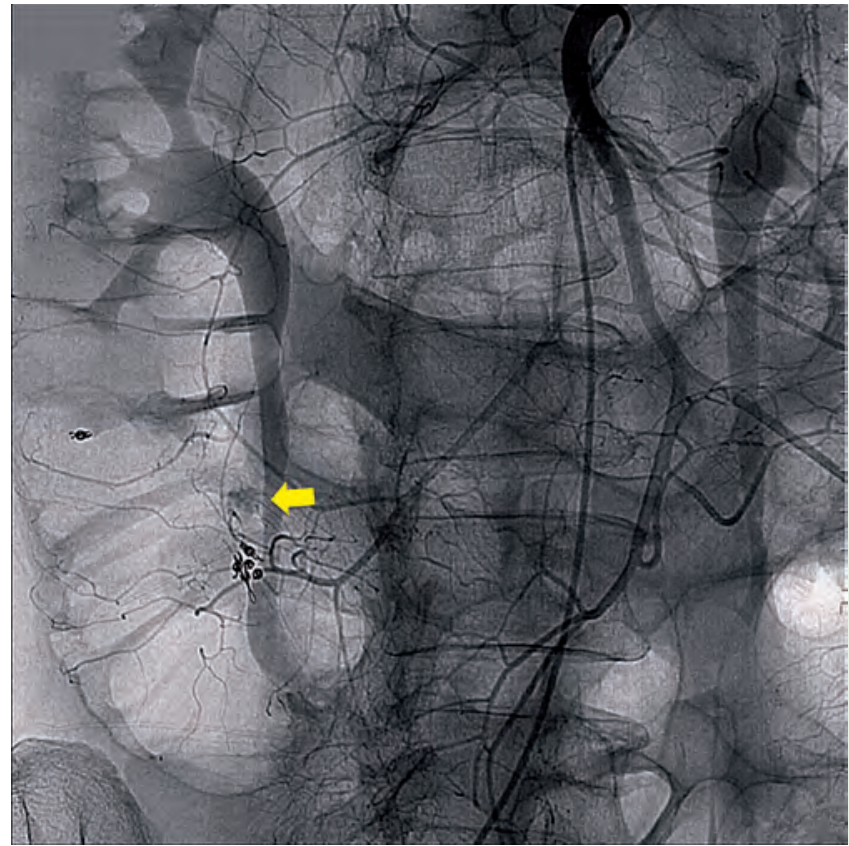

Fig. 2 Angiographic view showing extravasation of contrast media at a branch of the ileocolic artery (arrow). A few metal clips are seen in the vicinity.

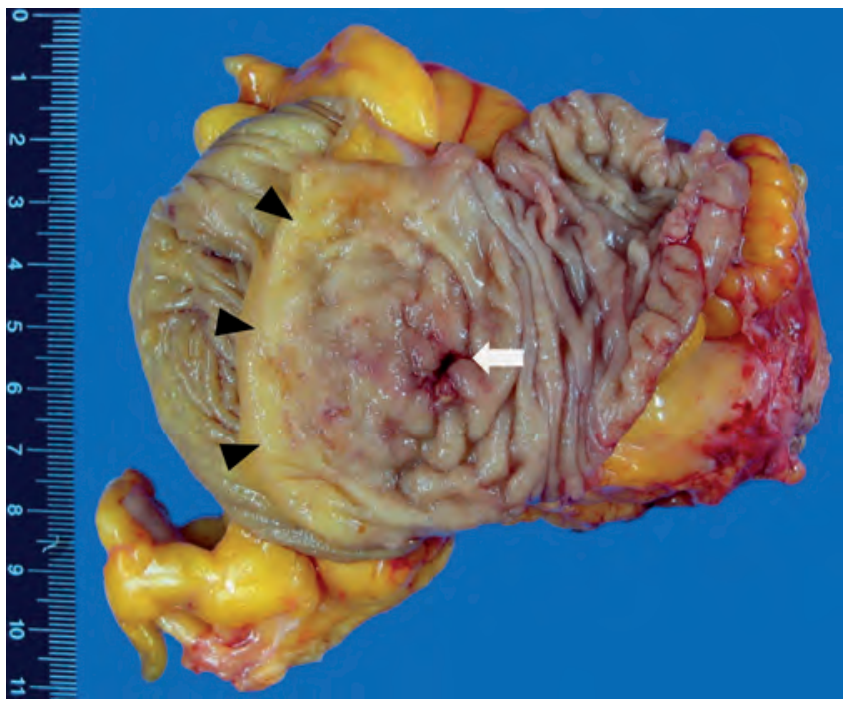

Fig. 3 Gross view of the ileocecectomy specimen, showing the diverticulum (arrow) at the junction of the ileocecal valve (arrow heads) and the terminal ileum.

where. The patient recovered uneventfully and had no further gastrointestinal bleeding.

Although colonoscopy can define the cause in most patients with lower gastrointestinal bleeding, no bleeding site is identified in $10 \%-20 \%$ of cases [4]. In such cases, an important cause may be an incomplete workup that overlooked the ileocecal region [5]. Terminal ileal diseases, such as Crohn's ileitis, Meckel's diverticulum, ulcers, and vascular ectasia, are responsible for $2 \%-9 \%$ of all lower gastrointestinal bleeding [3]. The present case highlights the importance of careful inspection of the ileocecal valve and terminal ileum in patients with lower gastrointestinal bleeding.

Endoscopy_UCTN_Code_CCL_1AD_2AF 


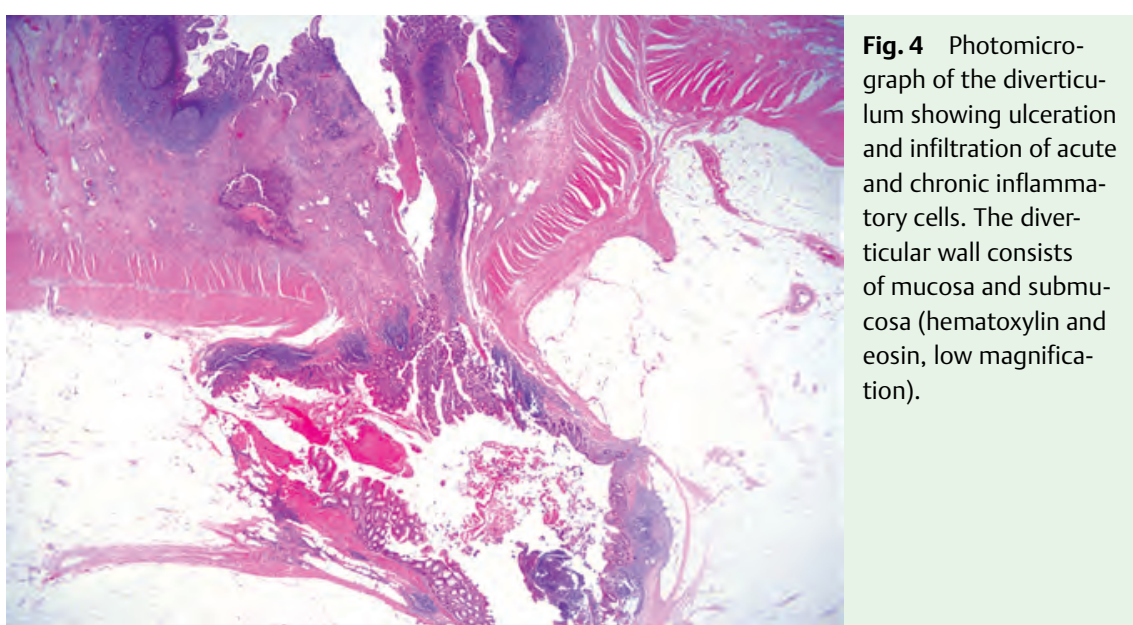

J. Shim, J. Y. Jang, Y. Hwangbo,

S. H. Dong, H. J. Kim, B. H. Kim, Y. W. Chang, R. Chang

Division of Gastroenterology and Hepatology, Department of Internal Medicine, Kyung Hee University, School of Medicine, Seoul, Korea
3 Zuccaro G Jr. Management of the adult patient with acute lower gastrointestinal bleeding. American College of Gastroenterology. Practice Parameters Committee. Am J Gastroenterol 1998; 93: 1202 - 1208

4 Green $B T$, Rockey DC. Lower gastrointestinal bleeding management. Gastroenterol Clin North Am 2005; 34: 665 - 678

5 Ohyama T, Sakurai Y, Ito $M$ et al. Analysis of urgent colonoscopy for lower gastrointestinal tract bleeding. Digestion 2000; 61: 189-192

Bibliography

DOI $10.1055 / \mathrm{s}-0029-1214858$

Endoscopy 2009; 41: E202-E203

(c) Georg Thieme Verlag KG Stuttgart · New York . ISSN 0013-726X

Corresponding author

\section{J. Y. Jang, MD}

Department of Internal Medicine

Kyung Hee University Hospital

1 Hoegi-dong

Dongdaemoon-gu

Seoul 130-702

Korea

Fax: +082-2968-1848

jyjang@khu.ac.kr 